International

Medical Society

http://imedicalsociety.org

\title{
Spontaneous Rupture of the Achilles Tendon
}

\author{
George Nilton Nunes Mendes', André Luis Sant'Anna1, \\ Francisco Bruno Celião Cabral2, \\ Jully Graziela Coelho Campos Couto', \\ Woneska Rodrigues Pinheiro ${ }^{3}$, Lillyane Medeiros Pereira1, \\ Hermes Melo Teixeira Batista ${ }^{1,2,3}$
}

\section{Abstract}

Introduction: The Achilles tendon is the largest and most resistant tendon of the human body and the incidence of spontaneous rupture has increased in recent decades, especially because of the appearance and wide use of quinolones, which use is associated with this pathology.

Objective: Case report of case of spontaneous rupture of the Achilles tendon in patients without predisposing risk factors. Method: case report based on the records of the patient and search in literature.

Discussion: Spontaneous rupture of the Achilles tendon is more common in men aged between 30 and 50 years old and has an incidence of 1:100,000 in the general population. However, there is a rare entity, the spontaneous rupture of the Achilles tendon (RETA), which it is due to chronic inflammation of the tendon.

Conclusion: Spontaneous rupture of the Achilles tendon is a rare entity, but should be suspected in patients who present acute pain condition or maybe worsened chronic pain, particularly when associated with the chronic use of corticosteroids or quinolones, or any of the cited predisposing factors.

\section{Introduction}

The Achilles tendon (Achilles tendon) is the largest, widest and resistant tendon of the human body. [1] The breaking of this body structure, although rare, is the most prevalent in large tendons of
1 College of Medicine Estácio from Juazeiro do Norte,Ce.

2 Regional Hospital of Cariri, Ce.

3 Design and scientific writing laboratory FMABC Santo André/SP.

Contact information:

Hermes Melo Teixeira Batista.

” hermesmelo@oi.com.br

Keywords

Achilles Tendon; Tendon

Rupture; Quinolones. 
the lower limbs, corresponding to $20 \%$ of the cases. [2, 3] In addition, it is known that spontaneous rupture occurs mainly in the elderly. [1] The main risk factors for tendon rupture include: mechanical injury, chronic tendinopathy, prolonged use of corticosteroids, use of quinolone antibiotics, in addition to rheumatoid arthritis, chronic kidney disease and diabetes mellitus. [4-6] The most important symptom is the sudden pain in the ankle; being or not associated with prodromal signs. [7] The treatment is surgical in the majority of the cases, but can also be a non-surgical treatment with resting of the limb; analgesics and anti-inflammatories also have been used with good results. [7-9]

Its incidence is estimated at 18 per 100,000 people in the general population and 1 per 250,000 patients treated with quinolones. The literature shows an increase in the number of reported cases. [7, 11]

This article aims to describe case of spontaneous rupture of the Achilles tendon in patients without associated risk factors and described in the relevant literature.

\section{Clinical Case}

Female patient, 62 years old, hypertensive, came at the service complaining of chronic pain in her right ankle, two months evolving with sudden worsening of pain not associated with sudden movements. The patient just had medical history of hypertension and this was being controlled with the use of captopril $50 \mathrm{mg} /$ day. She did not report the use of other medication. She had surgical history of perineoplasty and cholecystectomy. At the physical exam she presented pain on passive movement and swelling of right ankle, ultrasonography of the ankle was performed which showed a transfixing rupture of the right Achilles tendon. After 2 weeks under medication treatment and physical therapy, the patient did an MRI of the right ankle, which showed a rupture of the right calcaneal tendon and chronic tendinopathy in the pivot with inte- grity of the other flexors. She was submitted to surgical reconstruction of the Achilles tendon, with full suspension of the symptoms (Figures 1 to 3). She returned to the orthopedic consulting room after 30 days without complaints. Histopathological exam revealed: degenerative changes with extensive areas of necrosis and foci of dystrophic calcification.

\section{Discussion}

Achilles tendon rupture usually occurs after the sudden and forced movement of the ankle joint. It is more common in men aged between 30 and 50 years old without histologic evidence of inflammation. However, there is a rare entity, the spontaneous rupture of the Achilles tendon (RETA) that its appearance is not related to the sharp movement of the joint, but there is histologic evidence of chronic inflammation of the tendon. The RETA is associated with prolonged use of corticosteroid and quinolone class of antibiotics also can occur in patients with chronic renal disease, Reiter's syndrome, rheumatoid arthritis, systemic lupus erythematosus and hypercholesterolemia. This makes the case specific because there was no evidence of conditions that would predispose to chronic lesion present on histopathological examination.

The main clinical manifestation is the sudden leg pain, but the patient may also have difficulty wandering and loss or reduction of the strength of the lower limbs. In the case described above the symptom was like what the literature says: the patient presented sudden leg pain.

The diagnosis is made by history, physical examination and ankle ultrasound. At the physical examination we may feel a gap in the tendon and diagnosis should be confirmed by ultrasound. Magnetic resonance imaging may also be used for diagnosis. $[7,10,14]$

The treatment can be performed conservatively, or by surgery, usually in the surgery a primary suture 
of the lesion is made with satisfactory results, which was applied in the patient's case.

\section{Conclusion}

Spontaneous rupture of the calcaneal tendon is a rare entity, but it should be suspected in patients with acute pain or worsened chronic pain mainly when associated to chronic use of corticosteroids or quinolones, or any of the factors mentioned previously.

\section{References}

1. Kotnis RA, Halstead JC, Hormbrey PJ. Atraumatic bilateral Achilles tendon rupture: an association of systemic steroid treatment. J Accid Emerg Med. 1999; 16(5): 378-379

2. Habusta SF. Bilateral simultaneous rupture of the Achilles tendon. A rare traumatic injury. Clin Orthop 1995; 320:231-4

3. Rao SK, Navadgi BC, Vasdev A. Bilateral spontaneous rupture of Achilles tendons: A case report. Journal of Orthopaedic Surgery. 2005; 13(2):178-18

4. Orava S, Hurme M, Leppilahti J. Bilateral Achilles tendon rupture: a report on two cases. Scand J Med Sci Sports. 1996 Oct; 6(5):309-12.

5. Lewis TG. A rare case of ciprofloxacin-induced bilateral rupture of the Achilles tendon. BMJ Case Rep. 2009; 2009: bcr08.2008.0697

6. Huang GS. Spontaneous Achilles tendon rupture in a diabetic neuropathy patient on long-term hemodialysis. Q J Med. 2012; 105:1221-1222

7. Taylor TL, Simon D, Feibel R. Idiopathic simultaneous bilateral Achilles tendon rupture. BMJ Case Rep. 2009; 2009: bcr07.2009.2055.

8. Khanzada Z, Rethnam U, Widdowson D, Mirza A. Bilateral spontaneous non-traumatic rupture of the Achilles tendon: a case report. J Med Case Reports. 2011; 5: 263
9. Zhang S. Treatment of A Case of Spontaneous Rupture of Achille's Tendon. Journal of Traditional Chinese Medicine. 2003; 23(2): 113-114

10. Kawtharani F, Masrouha KZ, Afeiche N. Bilateral Achilles Tendon Ruptures Associated with Ciprofloxacin Use in the Setting of Minimal Change Disease: Case Report and Review of the Literature. The Journal of Foot \& Ankle Surgery. 2014 Sep: 1-3

11. Seidel J, Clarke T, Mathew B. To cipro or not to cipro: bilateral achilles ruptures with the use of quinolones. 2015 Mar; 105(2):185-8

12. Azuma N et. Al. A Case of Achilles Tendon Rupture in a patient of Refractory Reiter's Syndrome. Japanese Journal of Clinical Immunology. 2008; 31(2): 113-18

13. Carmont MR, Maffulli N. Achilles tendon rupture following surgical management for tendinopathy: a case report. BMC Musculoskelet Disord. 2007; 8: 19.

14. Kocaoglu B et. Al. Evaluation of absorbable and non absorbable sutures for repair of achilles tendon rupture with a sutureguiding device. Foot Ankle Int. 2015 Jun; 36(6):691-5

15. Rocha ES, Rose GJ, Schivinski CIS. Level of physical activity and functional in athletes children. Journal of Human Growth and Development. 2014; 24(2):127-34
Publish in International Archives of Medicine

International Archives of Medicine is an open access journal publishing articles encompassing all aspects of medical science and clinical practice. IAM is considered a megajournal with independent sections on all areas of medicine. IAM is a really international journal with authors and board members from all around the world. The journal is widely indexed and classified Q2 in category Medicine. 